\title{
(2) OPEN ACCESS \\ Hidden breast cancer after breast augmentation, not presenting as a hypoechoic mass lesion, diagnosed using colour Doppler ultrasound
}

\author{
Akihiro Fujimoto 다, Yoshimasa Kosaka, Takahiro Hasebe, Toshiaki Saeki
}

Breast Oncology Service, Saitama Medical University International Medical Center, Hidaka, Saitama, Japan

\section{Correspondence to} Mr Akihiro Fujimoto; afujimot@saitama-med.ac.jp

Accepted 23 July 2021

Check for updates

(c) BMJ Publishing Group Limited 2021. Re-use permitted under CC BY-NC. No commercial re-use. See rights and permissions. Published by BMJ.

To cite: Fujimoto A, Kosaka Y, Hasebe T, et al. BMJ Case Rep 2021;14:e242742. doi:10.1136/bcr-2021242742

\section{SUMMARY}

The main concern after breast augmentation with silicone injection is that silicone granulomas make it difficult to detect breast cancer. A case of breast cancer was diagnosed using colour Doppler ultrasound (CD) to detect an non-palpable mass not presenting as a hypoechoic mass lesion. An 83-year-old woman was incidentally found to have a lesion in her right breast, which was injected with silicone, showing 18F-fluorodeoxyglucose (FDG) uptake; the lesion was suspected to be breast cancer or silicone granuloma. A mass at the FDG uptake site was not detected on ultrasonography (US); however, observation using CD revealed a slightly hypoechoic area with hypervascularity. Core needle biopsy showed invasive ductal carcinoma. Patients in whom US does not reveal lesions after breast augmentation with silicone injection should undergo $C D$ to detect hypervascularised tissue. To prevent falsenegative biopsy results, CD is essential to detect cancer at suspected sites.

\section{BACKGROUND}

Breast augmentation with silicone injection, performed in the 1950s and 1960s, is currently prohibited due to safety concerns. ${ }^{1}{ }^{2}$ However, there are still a certain number of elderly people who underwent breast augmentation with silicone injection. Some reports show that breast cancer arises after breast augmentation with silicone injection. Common screening methods, including palpation, mammography (MMG) and ultrasonography (US), are ineffective for detecting breast cancer due to the influence of silicone granulomas, which makes diagnosis challenging. ${ }^{1}$ US findings for breast cancer with mass lesions are usually visualised as hypoechoic masses. The presence of hypervascular areas on colour Doppler ultrasound (CD) suggests malignant tumours. ${ }^{3}$ In this case, a lesion showing 18F-fluorodeoxyglucose (FDG) uptake was incidentally identified by FDG-positron emission tomography/CT (PET/CT) after breast augmentation with silicone injection; however, the tumour was not palpable and US did not show any mass lesion. A slightly hypoechoic area showing hypervascularity was observed on $\mathrm{CD}$; thus, core needle biopsy was performed and early stage breast cancer was diagnosed.

\section{CASE PRESENTATION}

The patient was an 83-year-old postmenopausal woman with a paternal family history of gastric cancer. The patient had a history of colon cancer and Hashimoto's disease. She underwent breast augmentation with silicone injection approximately 60 years ago and underwent surgery for colon cancer approximately 1 year ago. A PET/CT was done to detect colon cancer recurrence. During this time, a lesion showing FDG uptake was incidentally detected in her right breast and was suspected to be breast cancer (figure 1A,B). Diffuse undulations were palpated on both sides of the breast, which is consistent with the influence of breast augmentation with silicone injection; however, no apparent mass was palpated near the FDG uptake area. MMG was not performed considering breast augmentation surgery. US did not show a clear hypoechoic mass lesion at the site corresponding to the FDG uptake site, but careful observation using $C D$ revealed a slight hypoechoic area with hypervascularity (yellow lesion in the schematic) (figure 2A,B). An US-guided core needle biopsy was performed (figure 2C,D), and invasive ductal carcinoma (IDC) was diagnosed based on the histological findings. Two punctures were made at the 12 o'clock position of the right breast, and cancer tissue was detected in both needle biopsy specimens. Immunohistochemical staining revealed positive expressions of oestrogen receptor and progesterone receptor. The human epidermal growth factor receptor-2 (HER-2) expression score was $2+$, but in situ hybridisation showed no amplification of the HER2 gene. US also revealed multiple hypoechoic masses with no vascularity in her right breast, near the FDG uptake site based on PET/CT images (red lesions in the schematic) (figure 2A,E). Silicone granulomas were suspected; thus, additional core needle biopsies were performed on one of the mass lesions (red lesions in the schematic) to rule out breast cancer. As expected, the diagnosis was silicone granuloma. PET/CT revealed the absence of axillary metastasis and distant metastasis, and revealed the maximum lesion diameter to be $25 \mathrm{~mm}$. Thus, the diagnosis was classified as stage IIA IDC (cT2N0M0) based on the eighth edition of the Union for International Cancer Control tumour-node-metastasis classification of malignant tumours. Right mastectomy and sentinel lymph node biopsy were performed. Postoperative pathological findings confirmed that the tumour was IDC with an infiltration diameter of $29 \mathrm{~mm}$. Therefore, the final diagnosis was stage IIA IDC (pT2N0M0). Macroscopic findings of the resected specimen revealed multiple silicone granulomas on the dorsal side of breast cancer mass 


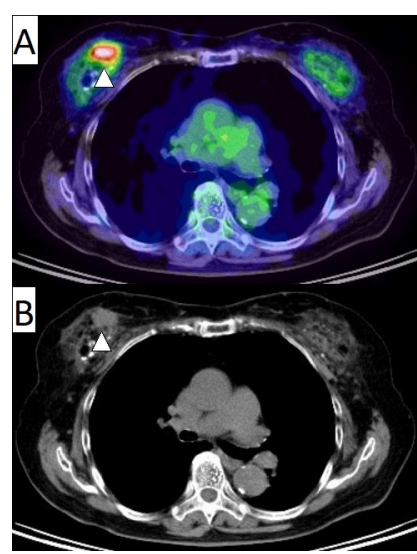

Figure 1 A lesion showing 18F-fluorodeoxyglucose uptake is observed in the right breast (A). A mass lesion is observed at the same site on plain computed tomography (B).

(figure 3). Histological findings showed that extensive granulomas were present in the mammary tissue surrounding or within the tumour, consistent with postsilicone injection findings. No axillary lymph node metastases were observed, but macrophage aggregation was prominent; this may have been due to the silicone injection.

\section{OUTCOME AND FOLLOW-UP}

Approximately 2 months have passed since the operation. The patient is currently undergoing adjuvant endocrine therapy with no apparent recurrence.

\section{DISCUSSION}

This case highlights two important clinical issues. First, in cases in which US does not show any mass after breast augmentation with silicone injection, CD should be used to detect
A
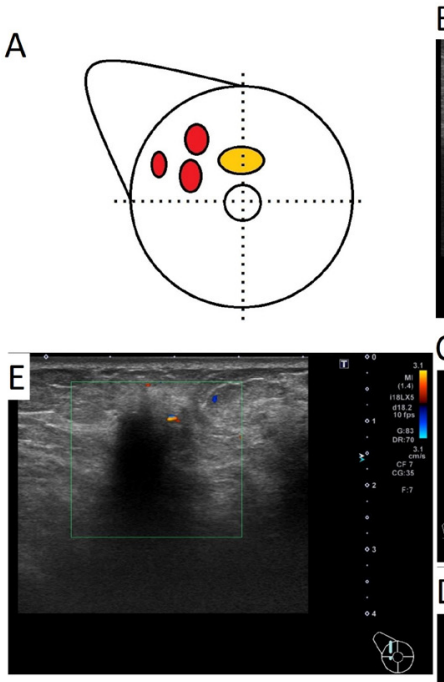

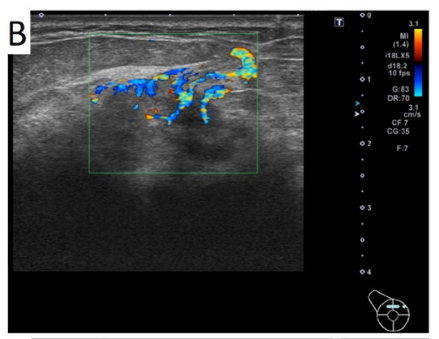

C]
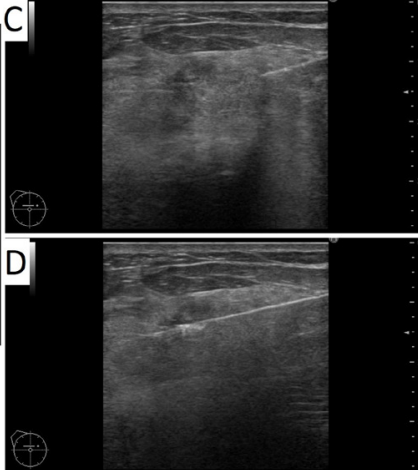

Figure 2 A schematic of ultrasonography findings (A). A slight hypoechoic area with hypervascularity (yellow lesion) is observed (B). An ultrasonography-guided core needle biopsy was performed (yellow lesion) (C, D). Multiple very hypoechoic masses without vascularity (red lesions) are observed (E).

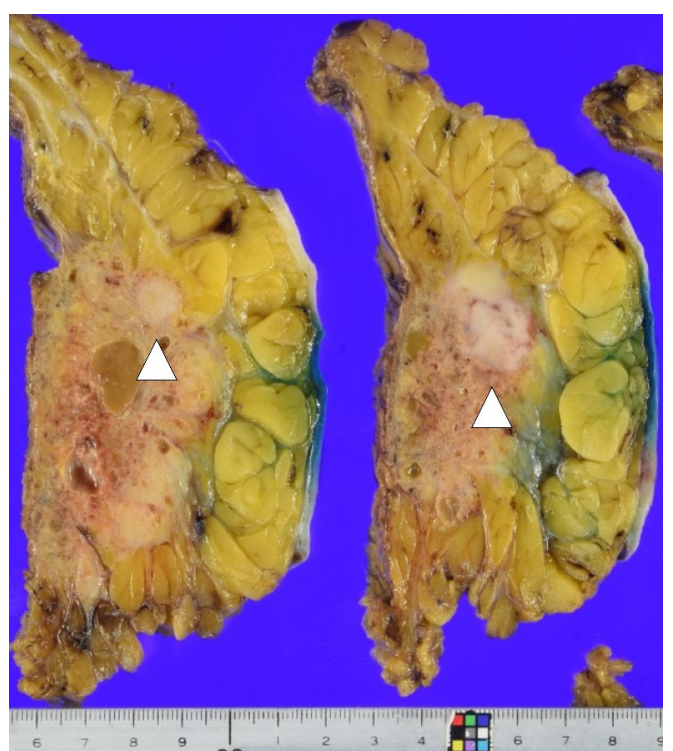

Figure 3 Macroscopic findings of the resected specimen (white arrowheads indicate the tumour) showing multiple silicone granulomas on the dorsal side of the breast cancer mass lesion.

hypervascularised areas. Second, to prevent false-negative biopsy results, it is important to perform CD to identify hypervascularisation that suggests cancer at suspected sites.

US usually shows breast cancer with mass lesions as hypoechoic masses. In this case, plain CT (figure 1B) and macroscopic findings of the resected specimen revealed that the breast cancer had a usual mass lesion. Therefore, if it were not for the silicone injection, the lesion was more likely to be palpable and appear as a hypoechoic mass. However, the lesion was not visualised as a hypoechoic mass. This may be due to the strong reflection, refraction, reverberation and attenuation of the ultrasonic beam resulting from fibrosis and silicon granulomas. ${ }^{1}$ In contrast, the FDG uptake site on PET/CT, that is, the site where the lesion was considered to be present, was carefully checked using CD to identify hypervascularisation. The extent of vascularisation in and around lesions is helpful in distinguishing between benign and malignant tumours. ${ }^{3}$ Although in this case, the site of FDG uptake was a non-mass lesion, a slightly hypoechoic area compared with the surrounding area, suggesting that a biopsy was required. This is the first report of breast cancer diagnosed through biopsy of a non-palpable, non-hypoechoic mass lesion with hypervascularisation after breast augmentation.

When a significant uptake of FDG is observed in the breast, the positive-predictive value for breast cancer is very high at $96.6 \% .{ }^{4}$ Therefore, the lesion in this case was expected to be malignant. In contrast, FDG can also be taken up in case of acute and chronic inflammation, physiological lactation and benign localised breast masses, such as silicone granulomas, fat necrosis, fibroadenoma and postoperative changes. ${ }^{5}$ Several reports have shown that silicone granulomas show significant FDG uptake after breast augmentation, ${ }^{67}$ and FDG-uptake silicone granulomas were considered to be a differential diagnosis in this case. However, multiple non-vascular, hypoechoic masses without FDG uptake were also noted. In contrast, no hypoechoic mass was observed at the FDG uptake site. The hypoechoic masses seen were probably silicone granulomas, but to rule out breast cancer, an additional core needle biopsy was performed on one of the hypoechoic masses and were confirmed as silicone granulomas. Furthermore, the silicone granulomas in this case 
showed no vascularity; the absence of vascularisation suggests a non-malignant mass. ${ }^{8}$ Therefore, in patients who have undergone silicone injection, it is necessary to ensure that the site of core needle biopsy corresponds to the FDG uptake site. Without the accurate identification of the cancer site on US, only silicone granulomas can be diagnosed; the cancer site cannot be accurately biopsied, and the cancer cells may go undetected, especially in cases of non-palpable lesions.

Stereotactic-guided biopsy was reported to be useful for breast cancer diagnosis after breast augmentation with silicone injection when lesions are unidentifiable via US. ${ }^{9}$ It is common to not perform MMG after breast augmentation surgery due to quality control issues in screening for breast cancer and possible damage to the insertion. MMG findings are less likely to indicate mammographic abnormalities in the absence of any physical findings. ${ }^{8}$ However, while a history of silicone granulomas secondary to silicone injection may pose some difficulty, MMG cannot be considered ineffective. Therefore, for a quicker and more straightforward diagnosis, performing MMG should have been considered in this case. In addition, contrast-enhanced MMG may also have been effective for assessing breast vascularity in this case. Contrast-enhanced magnetic resonance imaging (MRI) may also be effective in detecting breast cancer after breast augmentation. ${ }^{10}$ However, even though the MRI findings strongly indicate the presence of cancer, a biopsy should be performed to confirm the diagnosis of cancer. Breast biopsy, most commonly performed under US guidance, is important to identify breast lesions on US. Although MRI-guided biopsies may be useful for diagnosing cancer after breast augmentation, ${ }^{11}$ this technique is only available in a limited number of facilities. In this case, because the lesion had already been identified on US, breast cancer was diagnosed using minimally invasive techniques.

In conclusion, CD should be actively used to detect hypervascularised areas to prevent false-negative biopsy results, especially when no lesions are detected on US. While CD was helpful in this case and is increasingly suggested as a relatively straightforward adjunct in complex and challenging cases, it may not be applicable to all cases; further research on its value is required. Breast augmentation with silicone injections is no longer performed and only the elderly has undergone this method in the past, however similar problems are expected to arise in case of silicone breast implant (SBI) injury. SBI is widely used for breast augmentation and breast reconstruction. In this case, breast cancer was incidentally found by PET/CT, but the lesion was initially non-palpable and asymptomatic, thus, making it difficult to detect breast cancer by US screening alone. Breast cancer screening using MMG may be required even after breast augmentation, but due care must be taken during the examination. Furthermore, PET/CT and MRI are not commonly used in screening for breast cancer, but these methods may be considered after breast augmentation, especially when lesions are not palpable or easily visible on US.
Learning points

- Silicone granulomas after breast augmentation using silicone injection make it difficult to detect breast cancer.

- When ultrasonography does not show any mass lesion, colour Doppler ultrasound should be used to detect hypervascularised areas.

- To prevent false-negative biopsy results, it is important to use colour Doppler ultrasound to identify cancer at suspected sites.

Contributors Conception and design of study: AF and YK. Acquisition of data: AF and TH. An alysis and/or interpretation of data: AF and YK. Drafting the manuscript: AF. Revising the manuscript critically for important intellectual content: YK and TS. Approval of the version of the manuscript to be published: AF, YK, TH and TS

Funding The authors have not declared a specific grant for this research from any funding agency in the public, commercial or not-for-profit sectors.

Competing interests TS reports personal fees from ASKA Pharmaceutical, Astra Zeneca K.K., Eisai, Ono Pharmaceutical, Taiho Pharmaceutical, Takeda Pharmaceutical, Chugai Pharmaceutical, Eli Lilly Japan K.K., Novartis Pharma K.K., Pfizer, MiRTeL, Meiji Seika Pharma, Nippon Kayaku, grants from Eisai, Kyowa Hakko Kirin, Taiho Pharmaceutical, Chugai Pharmaceutical, Nippon Kayaku, outside the submitted work.

Patient consent for publication Obtained.

Provenance and peer review Not commissioned; externally peer reviewed.

Open access This is an open access article distributed in accordance with the Creative Commons Attribution Non Commercial (CC BY-NC 4.0) license, which permits others to distribute, remix, adapt, build upon this work non-commercially, and license their derivative works on different terms, provided the original work is properly cited and the use is non-commercial. See: http://creativecommons.org/ licenses/by-nc/4.0/.

\section{ORCID iD}

Akihiro Fujimoto http://orcid.org/0000-0003-4261-7984

\section{REFERENCES}

1 Cheung Y-C, Lee K-F, Ng S-H, et al. Sonographic features with histologic correlation in two cases of palpable breast cancer after breast augmentation by liquid silicone injection. J Clin Ultrasound 2002:30:548-51.

2 Scaranelo AM. De Fatima Ribeiro Maia M. sonographic and mammographic findings of breast liquid silicone injection. J Clin Ultrasound 2006;34:273-7.

3 Watanabe T, Kaoku S, Yamaguchi T, et al. Multicenter prospective study of color Doppler ultrasound for breast masses: utility of our color Doppler method. Ultrasound Med Biol 2019:45:1367-79.

4 Avril N, Rosé CA, Schelling M, et al. Breast imaging with positron emission tomography and fluorine-18 fluorodeoxyglucose: use and limitations. J Clin Oncol 2000;18:3495-502

5 Adejolu M, Huo L, Rohren E, et al. False-Positive lesions mimicking breast cancer on FDG PET and PET/CT. AJR Am J Roentgenol 2012;198:W304-14.

6 Chen C-J, Lee B-F, Yao W-J, et al. A false positive F-FDG PET/CT scan caused by breast silicone injection. Korean J Radiol 2009;10:194-6.

7 Fernandes Vieira V, Dubruc E, Raffoul W, et al. Bilateral silicone granulomas mimicking breast cancer recurrence on 18F-FDG PET/CT. Clin Nucl Med 2021;46:140-1.

8 Tanaka Y, Morishima I, Kikuchi K. Invasive micropapillary carcinomas arising 42 years after augmentation mammoplasty: a case report and literature review. World J Surg Oncol 2008;6:33

9 Nakahori R, Takahashi R, Akashi M, et al. Breast carcinoma originating from a silicone granuloma: a case report. World J Surg Oncol 2015;13:72.

10 Youk JH, Son EJ, Kim E-K, et al. Diagnosis of breast cancer at dynamic MRI in patients with breast augmentation by paraffin or silicone injection. Clin Radiol 2009;64:1175-80.

11 Cheung Y-C, Chen S-C, Lo Y-F. Enhanced MRI and MRI-guided interventional procedures in women with asymptomatic silicone-injected breasts. ScientificWorldJournal 2012:2012:1-6. 
Copyright 2021 BMJ Publishing Group. All rights reserved. For permission to reuse any of this content visit https://www.bmj.com/company/products-services/rights-and-licensing/permissions/

BMJ Case Report Fellows may re-use this article for personal use and teaching without any further permission.

Become a Fellow of BMJ Case Reports today and you can:

- Submit as many cases as you like

- Enjoy fast sympathetic peer review and rapid publication of accepted articles

Access all the published articles

Re-use any of the published material for personal use and teaching without further permission

Customer Service

If you have any further queries about your subscription, please contact our customer services team on +44 (0) 2071111105 or via email at support@bmj.com.

Visit casereports.bmj.com for more articles like this and to become a Fellow 